\title{
Rhizobacteria Effect on Arsenic Migration and Translocation of Biogenic Elements in Plants
}

\section{G A Belogolova1, O N Gordeeva1, M G Sokolova², V I Poletaeva1, O B Vaishlya², M V Pastukhov', and B A Baenguev ${ }^{1}$}

${ }^{1}$ Laboratory of Environmental Geochemistry and Physical-Chemical Modeling, Vinogradov Institute of Geochemistry SB RAS, Irkutsk, Russia

${ }^{2}$ Laboratory of Plant Resistance Physiology, Siberian Institute of Plant Physiology and Biochemistry SB RAS, Irkutsk, Russia

${ }^{3}$ Department of Vertebrate Zoology and Ecology, Tomsk State university, Tomsk, Russia

\section{Abstract}

The study was aimed at the transformation of arsenic compounds in the rhizosphere, its accumulation in plants, $\mathrm{P}$ and $\mathrm{Si}$ translocation to plants under the influence of Bacillus megaterium var. phosphaticum, and Bacillus mucilaginosus with various forms of As compounds in the soil. The authors describe the maximum effect of Bacillus megaterium var. Phosphaticum strain on As migration, its mobilization and

Corresponding Author:

G A Belogolova

gabel@igc.irk.ru

Received: 25 October 2019

Accepted: 15 November 2019

Published: 25 November 2019

Publishing services provided by Knowledge E

(c) G A Belogolova et al. This article is distributed under the terms of the Creative Commons Attribution License, which permits unrestricted use and redistribution provided that the original author and source are credited.

Selection and Peer-review under the responsibility of the AgroSMART 2019 Conference Committee.

\section{G OPEN ACCESS} immobilization in the rhizosphere due to arsenic leaching from mineral and difficult-todestroy compounds and its accumulation in plants. The forms of arsenic compounds were isolated from the rhizosphere based on sequential extraction procedures. The features of the inter-element As-P interaction in plants were established. With the intense accumulation of $A s$ in the rhizosphere inoculated with rhizobacteria, the intake of phosphorus into plants was not observed, as contrary to Si. The study of As and biogenic elements behavior under the influence of rhizobacteria is of great importance in the development of ecobiotechnologies related to soil remediation and crop production.

Keywords: rhizobacteria, soil, plants, arsenic, phosphorus, silicon, migration.

\section{Introduction}

Recently, the role of Plant Growth Promoting Rhizobacteria (PGPR) [1-3] and their contribution to the development of environmentally friendly crop production has been increasingly addressed. Yet, the interrelation of plants, soil and rhizobacteria remains an insufficiently studied biogeochemical sector. Rhizobacteria can play a significant role to stimulate the transformation of chemical compounds and their migration in a soil-plant system. Many soil bacteria are known to be highly resistant to arsenic and heavy metals but the mechanisms and processes of their interaction are still poorly understood. There is an opinion that rhizobacteria can transform heavy metal compounds into organometallic and other weakly mobile complexes that are adsorbed by bacteria and 
concentrated on the surface of plant roots [4]. Rhizobacteria can initiate the intake of biogenic elements into plants. It is known that some bacteria are able to adsorb trace minerals on the surface and accumulate them inside the cells [5]. In their early research, the authors addressed the ability of a complex biological preparation based on Azotobacter and Bacillus rhizobacteria to influence the phase state and migration of arsenic in the soil-plant system [6].

The present study was aimed at the mechanisms of As behavior in the soil -- plant -rhizobacteria system and the inter-element relation of arsenic and phosphorus. The main objective of the study was to analyze the effect of Bacillus megaterium var. phosphaticum strains and Bacillus mucilaginosus on the change in the speciation of As in soil and its accumulation in plants.

\section{Methods and Materials}

A simulation experiment to study the distribution of chemical elements in the soil-plant system under the influence of rhizobacteria was carried out in a phytotron chamber. The technogenic soil samples were selected near the industrial site of the Angarsk Metallurgical Plant (AMP) located in Svirsk (Baikal Region, Eastern Siberia). The plant used to produce white and gray arsenic from arsenopyrite concentrate. A dangerous source of arsenic, lead and other metal contamination was the workshop debris and dumped arsenic waste. Since 1949, the plant was deserted. As a result, soil contamination with arsenic penetrated to the entire territory of the town, with As amount exceeding the Soil Guideline Values (SGV) by 10--400 times in the soil around the dumps. The samples of soil for the experiment were selected at two sites from the upper level at a depth of $10--15 \mathrm{~cm}$. Site 1 is located $500 \mathrm{~m}$ from the main source of contamination and is used for agricultural purposes. The soil is soddy -- carbonate, lightly loamy. Site 2 is located 10 $\mathrm{m}$ from the AMP dumps. The soil here was formed of technosols with a trace of waste left from the production of arsenic concentrate.

Two Bacillus bacterial strains were used for the experiments. Phospho-bacterin (Bacillus megaterium var. Phosphaticum, strain PI-04, ACM B-2357 D) is a preparation based on live acid-forming soil bacteria that is able to mobilize phosphorus from an insoluble fraction into a form available for plants to stimulate plant rooting. Silicon-bacterin (Bacillus mucilaginosus, strain ACM B-1574) is a preparation based on silicate bacteria. The bacteria contained in this preparation secrete the silicase enzyme and provide silicon and other macro- and microelements from natural silicates to the rhizosphere of 
plants. Biological preparations developed at Tomsk State University are environmentally friendly, non-toxic, safe for humans and animals, plant growth stimulants.

Each soil from the two sites was divided into a control soil (without bacteria) and a soil that was used for two experiments. Cereals were grown on one of them -- oat Avena sativa $L$. and wheat Triticum aestivum $L$. -- with the soil being inoculated with B. megaterium var. phosphaticum, and B. mucilaginosus -- on the other. The vessels with a soil volume of up to $5 \mathrm{~kg}$ were used for growing the plants. Two solutions each with a concentration of a different bacterium at a rate of $5 \mathrm{ml}$ per 10 litres $(0.5 \mathrm{ml} / \mathrm{l})$ of water were applied into the soil by irrigation during planting and then after 5 days at a rate of $1 \mathrm{l} / \mathrm{m}^{2}$. The titer of bacteria in the working solution was $10^{6}$ cells $/ \mathrm{ml}$. After 35 days of growing on the technogenic soil of site 2 , the plants began to dry, thus failing to reach the mature state and the experiments at this stage were completed. For chemical analysis, the air-dried plants were used. The roots were pre-washed in running water. Chemical analysis of soil and plants was carried out based on several measurements (triple analysis) for control using standard samples. The soil surrounding the roots was used to conduct sequential extraction procedures to study the speciation of As. The technique [7], with some minor modifications utilized today to study particulate trace minerals in soil, to establish their mobility and bioavailability provided the basis for the research.

The chemical analysis of soil and plants was performed using scientific equipment of the certified analytical center of the collective use "Isotopic---geochemical investigations" at the Institute of Geochemistry, SB RAS. The Soil was analyzed by atomic absorption. The measurements were performed on 403 and 503 spectrometers of Perkin-Elmer company (USA). The measurement error did not exceed 5--10 \%. The chemical composition of plants was analyzed by inductively coupled plasma mass spectrometry (ICP-MS). A sensitive ICP-MS instrument with a magnetic sector ELEMENT 2 (Finnigan MAT, Germany), with double focusing and the ability to record a signal in different resolutions, was used. The measurement error did not exceed 5--7\%. The triple chemical analysis of dry plants and soil was carried out. To control the accuracy of the results, certified reference materials of composition were used (birch leaf BL-1, SSS 8923-2007, Canadian EC-1 pondweed, SSS 8921-2007, Cr-1 crop mixture, SSS 89222007); to control the analysis of the soil -- samples: CCS-1 (calcium carbonate sierozem); SDPS-2 (technogenic soil). 


\section{Results and Discussion}

Arsenic has a special significance for live organisms. It is reported as a very strong ecotoxicant and an essential chemical element for humans [8]. However, its biogeochemical value for plants is still poorly understood. The main human-induced source of environmental pollution with arsenic is pesticides and waste from mining and metallurgical enterprises. Much is known about the emission of As in the environment. However, As migration habits in the soil -- plant system under the influence of rhizobacteria are little addressed in plant production, which is explained by its high migration mobility and diverse speciation of compounds in soil. Soil bacteria play an important role in arsenic migration [9]. This is confirmed by the research. Arsenic contained in an easily exchangeable fraction is most mobile and available to plants, whereas carbonate bound, organically bound, and Fe oxide bound As have a lower mobility. These compounds represent the closest reserve that can be mobilized when some properties of the soil change (moisture, $\mathrm{pH}$, Eh). The fraction of easily reducible silicates is characterized by stronger As compounds bound on clay and silicate minerals.

The percentage distribution of As content relative to the amount of isolated fractions for the soil on which oats were grown, having a more developed root system among cereals, is shown in Fig. 1. Arsenic is reported to have high mobility, since its easily exchangeable form can go up to $40 \%$ off the amount of all fractions. The potentially mobile forms of arsenic (carbonate and organic) are also characterized by a high percentage. In the control soil (without bacteria), there is an increased mobilization of arsenic at site 1, which has agricultural significance, relative to technogenic site 2 . The speciation of Arsenic in the soil of site 2 is partly mineral in a form of arsenopyrite and other secondary mineral compounds; therefore, it is poorly mobile. This is evident in the control soil (Fig. 1). When inoculating the soil of site 2 with B. megaterium var. phosphaticum strain the minimum percentage of arsenic was distinguished in a solid residual fraction and a silicate fraction. There is a concurrent increase in its concentration with Fe oxides and more mobile fractions, as contrary to the control soil of site 2 . This indicates an increase in migration habit of $A$ s under the influence of $B$. megaterium var. phosphaticum that initiates the mobilization of mineral-bound arsenic in the rhizosphere (Fig. 1).

This trend is also clearly visible in absolute concentrations of arsenic in the rhizospheric when growing $A$. sativa oats and T. Aestivm wheat (Table 1). The concentration of As in easily exchangeable, carbonate-bound, organic-bound status and with Fe oxides under the influence of $B$. megaterium var. phosphaticum strain at site 2 is significantly 
increased (Table1). The easy exchangeable As status is the most toxic and can be easily admitted by plants. The increased concentrations of arsenic in the carbonate and organic fractions can also be transformed due to soil bacteria [9].

Arsenic is known to be well bound with Fe. The technogenic soil of site 2 contained high concentrations of $\mathrm{Fe}$ as a result of the destruction and oxidation of sulphide minerals. Rhizobacteria initiated the accumulation of a large amount of arsenic in the $\mathrm{Fe}$ oxide fraction. High accumulation of arsenic in the fraction of easily reducible silicates (Table 1) may be due to the adsorption of bacteria bound arsenic on clay and quartz minerals in the rhizosphere. Thus, $B$. megaterium var. phosphaticum rhizobacteria can more actively affect the migration processes of As in the rhizosphere due to its leaching from mineral and difficult to destroy forms and its concentration in the rhizosphere. It is known that the leaching of chemical elements from minerals by microorganisms can run very fast, just within a few days. This is shown through phosphorites [10].

In the plants grown on the soil with rhizobacteria, the mean concentration of As, relative to the control, increases (Table 2). This is mainly due to the accumulation of arsenic in the roots of the plants. In the above-ground portion of the plants at agricultural site 1 , the As content decreases or differs slightly from the control state. As concentration in the plants grown under the influence of $B$. megaterium var. phosphaticum rhizobacteria on site 2 is reported to be high (Table 2).

This rhizobacteria strain is capable of mobilizing phosphorus from the insoluble fraction in a plant-available form. In the present experiment, these bacteria did not initiate the accumulation of phosphorus in the plants (Table 3). The content of $P$ went down or slightly differed from the control state. However, rhizobacteria, particularly $B$. mucilaginosus strain, contributed to the translocation of $\mathrm{Si}$ into the plants. In some cases As is known to be absorbed by bacteria instead of phosphorus [11]. Some authors believe that arsenic is able to participate even in the metabolic processes of the bacterial cell, due to the corresponding chemical properties of arsenic and phosphorus. A decrease in phosphorus in plants with a high concentration of arsenic can be associated with toxic stress and inter-element interaction between these elements. As a result, arsenic competes with phosphorus in plants.

All in all, arsenic can be a phosphorus antagonist. Inter-element interactions between these elements may also affect the metabolism in the plant itself. The conclusion is that the $B$. megaterium var. phosphaticum strain has a high resistance to high concentrations of arsenic and in this case, unlike silicon, scarcely affects the translocation of phosphorus to plants. 
TABLE 1: Distribution of As concentrations $(\mathrm{mg} / \mathrm{kg})$ in various rhizospheric fractions with rhizobacteria and in a control soil to grow oats and wheat.

\begin{tabular}{|c|c|c|c|c|c|c|}
\hline \multirow[t]{2}{*}{ Fraction } & \multicolumn{2}{|c|}{ Bacillus mucilaginosus } & \multicolumn{2}{|c|}{$\begin{array}{l}\text { Bacillus megaterium var. } \\
\text { phosphaticum }\end{array}$} & \multicolumn{2}{|c|}{ Control } \\
\hline & $1^{a}$ & 2 & 1 & 2 & 1 & 2 \\
\hline \multicolumn{7}{|c|}{ Wheat } \\
\hline Mobile & $183 \pm 18.3^{b}$ & $165 \pm 16.5$ & $176 \pm 17.6$ & $866 \pm 86.6$ & $198 \pm 19.8$ & $201 \pm 20.1$ \\
\hline Carbonate & $107^{c} \pm 10.7$ & $74 \pm 7.4$ & $56 \pm 5.6$ & $407 \pm 40.7$ & $59 \pm 5.9$ & $116 \pm 11.6$ \\
\hline Organically bound & $24 \pm 2.4$ & $69 \pm 6.9$ & $42 \pm 4.2$ & $157 \pm 15.7$ & $27 \pm 2.7$ & $84 \pm 8.4$ \\
\hline Fe-ox. & $65 \pm 6.5$ & $200 \pm 20$ & $74 \pm 7.4$ & $700 \pm 70$ & $48 \pm 4.8$ & $200 \pm 20$ \\
\hline Silicate & $113 \pm 11.3$ & $593 \pm 59.3$ & $139 \pm 13.9$ & $2323 \pm 232$ & $113 \pm 11.3$ & $929 \pm 92.9$ \\
\hline Residual & $10.8 \pm 1.1$ & $42 \pm 4.2$ & $10.2 \pm 1.02$ & $90 \pm 9.0$ & $12 \pm 1.2$ & $40 \pm 4.0$ \\
\hline $\begin{array}{l}\text { Total } \\
\text { concentration }\end{array}$ & $520 \pm 52$ & $1300 \pm 130$ & $440 \pm 44$ & $4800 \pm 480$ & $550 \pm 55$ & $1600 \pm 160$ \\
\hline \multicolumn{7}{|c|}{ Oats } \\
\hline Mobile & $201 \pm 20.1$ & $153 \pm 15.3$ & $153 \pm 15.3$ & $678 \pm 67.8$ & $204 \pm 20.4$ & $175 \pm 17.5$ \\
\hline Carbonate & $73.8 \pm 7.4$ & $38 \pm 3.8$ & $61 \pm 6.1$ & $364 \pm 36.4$ & $59 \pm 5.9$ & $81 \pm 8.1$ \\
\hline Organically bound & $39 \pm 3.9$ & $142 \pm 14.2$ & $22 \pm 2.2$ & $132 \pm 13.2$ & $20 \pm 2.0$ & $65 \pm 6.5$ \\
\hline Fe-ox. & $46 \pm 4.6$ & $330 \pm 33$ & $50 \pm 5$ & $690 \pm 69$ & $55 \pm 5.5$ & $180 \pm 18$ \\
\hline Silicate & $119 \pm 11.9$ & $1232 \pm 123$ & $113 \pm 11.3$ & $255 \pm 25.5$ & $203 \pm 20.3$ & $792 \pm 79.2$ \\
\hline Residual & $12.4 \pm 1.2$ & $50 \pm 5.0$ & $14.2 \pm 1.4$ & $85 \pm 8.5$ & $11 \pm 1.1$ & $52 \pm 5.2$ \\
\hline $\begin{array}{l}\text { Total } \\
\text { concentration }\end{array}$ & $510 \pm 51$ & $1130 \pm 113$ & $525 \pm 52.5$ & $3100 \pm 310$ & $480 \pm 48$ & $1300 \pm 130$ \\
\hline
\end{tabular}

a. Sites (hereafter): 1 -- agricultural soil 500m from AMP, 2 -- technogenic soil 10m from AMP dumps.

b. Hereinafter: mean concentration $\pm \mathrm{SD}, \mathrm{n}=$ triple analysis. Values are not significantly different at $p<0.05$.

c. Italicized is As content above control for each site.

TABLE 2: Distribution of As concentrations in the plants grown on the soil with rhizobacteria and on the control soil (mg/kg of dried substance).

Plants
Triticum aestivm
shoot
Triticum aestivm
root
Avena sativa
shoot
Avena sativa root
Mean
concentration

Bacillus muci $1^{a}$
$3.1 \pm 0.16^{b}$
$\begin{gathered}108.0^{c .} \pm \\ 5.4\end{gathered}$
$3.2 \pm 0.16$
$134.0 \pm 6.7$
62.0

Bacillus megaterium var.

\begin{tabular}{c}
2 \\
\hline $8.5 \pm 0.43$ \\
\hline $91.0 \pm 4.6$ \\
\hline $8.8 \pm 0.44$ \\
\hline $107.0 \pm 5.5$ \\
\hline 54.0
\end{tabular}
phosphaticum

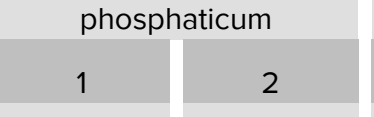

$3.1 \pm 0.16$

$143.0 \pm 7.2$

$3.3 \pm 0.17$

$151.0 \pm 7.6$

75.0

\begin{tabular}{|c|c|}
\hline \multicolumn{2}{|c|}{ Control } \\
\hline 1 & 2 \\
\hline $3.0 \pm 0.15$ & $4.9 \pm 0.25$ \\
\hline $83.0 \pm 4.2$ & $103.0 \pm 5.2$ \\
\hline $3.3 \pm 0.17$ & $4.9 \pm 0.25$ \\
\hline $156.0 \pm 7.8$ & $88.0 \pm 4.4$ \\
\hline 61.0 & 50.2 \\
\hline
\end{tabular}




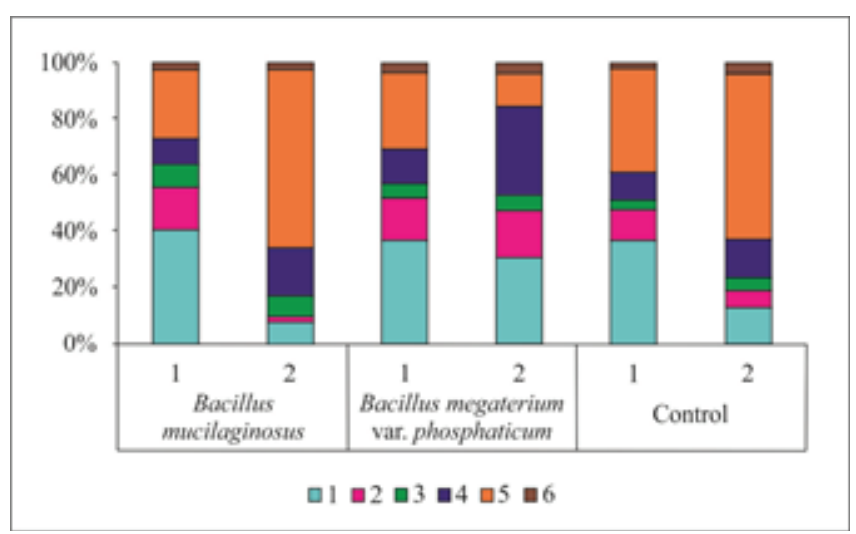

Figure 1: Concentration of As in sequential extractions (percent of the amount of fractions) from the rhizosphere with soil bacteria and in the control soil with oat growing. Fractions: 1 -- mobile; 2 -- carbonate bound; 3 -- organically bound; 4 -- Fe oxide bound; 5 -- easily reducible silicates; 6 -- residual fraction. Sites: 1 -- agricultural soil 500 m from AMP, 2 -- technogenic soil 10 m from AMP dumps.

TABLE 3: Distribution of P, Si concentrations (\% per dried substance) in the plants grown on the soil with rhizobacteria and the control soil.

\begin{tabular}{|c|c|c|c|c|c|c|}
\hline \multirow[t]{2}{*}{ Plants } & \multicolumn{2}{|c|}{ Bacillus mucilaginosus } & \multicolumn{2}{|c|}{$\begin{array}{l}\text { Bacillus megaterium var. } \\
\text { phosphaticum }\end{array}$} & \multicolumn{2}{|c|}{ Control } \\
\hline & 1 & 2 & 1 & 2 & 1 & 2 \\
\hline $\begin{array}{l}\text { Triticum aestivm } \\
\text { shoot }\end{array}$ & $0.47^{d} 1.0^{e}$ & $0.580,47$ & $0.631,27$ & 0.580 .26 & 0.661 .0 & 0.620 .27 \\
\hline $\begin{array}{l}\text { Triticum aestivm } \\
\text { root }\end{array}$ & 0.391 .8 & 0320.71 & 0.51 .8 & 0.330 .7 & 0.51 .2 & $0.330,35$ \\
\hline $\begin{array}{l}\text { Avena sativa } \\
\text { shoot }\end{array}$ & 0.61 .25 & 0.580 .64 & 0.451 .18 & 0.620 .27 & 0.510 .84 & 0.610 .37 \\
\hline Avena sativa root & 0.461 .83 & 0.211 .36 & 0.392 .0 & 0.260 .6 & 0.441 .8 & 0.250 .83 \\
\hline
\end{tabular}

\section{Conclusion}

Thus, the authors establish the effect of different rhizobacteria strains on the translocation of As, P, Si into plants. It is shown that $B$. megaterium var. phosphaticum has a high bioactivity with respect to As. This strain is able to change the mineral and bound arsenic compounds and initiate its transfer into mobile forms, well available to the root system of plants.

The experiment established the inter-element interaction of $A$ s and $P$ in plants. With the intensive accumulation of $A s$ in the rhizosphere inoculated with rhizobacteria, the phosphorus concentration in plants decreases, which is due to their far corresponding chemical properties. The experiment also established the possibility of translocation of $S i$ into plants under the influence of $B$. mucilaginosus strain. The results obtained can be of fundamental interest for elucidating the mechanisms of arsenic behavior in the soil -- 
plant system and its relationship with biogenic elements when subject to rhizobacteria. The study of the biogeochemical activity of arsenic in the rhizosphere can also be of great practical importance, due to the possibility to use strains of living soil bacteria $B$. megaterium var. phosphaticum and $B$. mucilaginosus for soil remediation, plant growing and nanotechnology.

\section{Acknowledgment}

The study was conducted within the framework of the project IX 127.1. (0350-20160027), with financial support from the RFBR grant No. 15-05-03919 and the grant from the Tomsk State University Competitiveness Enhancement Program.

\section{References}

[1] Vimal, S.R., Singh, J.S., Arora, N.K. et al. (2017). Soil-plant-microbe interactions in stressed agriculture management. A review. Pedosphere, vol. 27(2), pp. 177--192.

[2] Lugtenberg, B.J., Kamilova, F. (2009). Plant growth-promoting rhizobacteria. Annu. Rev. Microbiol, vol. 63, pp. 541--556.

[3] Barea, J.M. (2015). Future challenges and perspectives for applying microbial biotechnology in sustainable agriculture based on a better understanding of plantmicrobiome interactions. J. Soil Sci. Plant Nut., vol. 15(2), pp. 261--282.

[4] Khan, M.S., Zaidi, A., Wani, P.A. et al. (2009). Role of plant growth promoting rhizobacteria in the remediation of metal contaminated soils. Environ. Chem. Lett., vol. 7, pp. 1--19.

[5] Tabak, H.H., Lens, P., van Hullebusch, E.D. et al. (2005). Developments in Bioremediation of soils and sediments polluted with metals and radionuclides -- 1. Microbial processes and mechanisms affecting bioremediation of metal contamination and influencing metal toxicity and transport. Rev. Environ. Sci. BioTechnol., vol. 4, pp. 115--156.

[6] Belogolova, G.A., Sokolova, M.G., Gordeeva, O.N. et al. (2015). Speciation of arsenic and its accumulation by plants from rhizosphere soils under the influence of Azotobacter and Bacillus bacteria. J. Geochem. Explor., vol. 149, pp. 52--58.

[7] Tessier, A., Campbell, P.G.C., Bisson, M. (1979). Sequential extraction procedures for the speciation of particulate trace metals. Anal. Chem., vol. 51, pp. 844--851.

[8] Rebrov, V.G., Gromova, O.A. (2003). Vitamins and trace minerals. Moscow: Alev-V, p. 670. 
[9] Fitz, W.J., Wenzel, W.W. (2002). Arsenic transformation in the soil-zhizosphere-plant system: fundamentals and potential application to phytoremediation. J. Biotechnol., vol. 99, pp. 259--278.

[10] Vaishlya, O.B., Amyago, D.M., Guseva, N.V. (2013). Role of Bacillus Mucilaginosus at Silicon Biogeochemical Cycle in a System Soil -- Plant. Mineral. Mag., vol. 77, p. 2383.

[11] Oremland, R.S., Chad, W.S., Wolfe-Simon, F. et al. (2009). Arsenic in the Evolution of Earth and Extraterrestrial Ecosystems. Geomicrobiology, vol. 26, pp. 522--536. 